\title{
Early Oxygen Uptake Recovery Following Exercise Testing in Children with Chronic Chest Diseases
}

\begin{tabular}{|c|c|}
\hline Journal: & Pediatric Pulmonology \\
\hline Manuscript ID: & PPUL-08-0252.R1 \\
\hline Wiley - Manuscript type: & Original Article \\
\hline $\begin{array}{l}\text { Date Submitted by the } \\
\text { Author: }\end{array}$ & 02-Nov-2008 \\
\hline Complete List of Authors: & $\begin{array}{l}\text { Stevens, Daniel; University of Exeter, Children's Health and } \\
\text { Exercise Research Centre } \\
\text { Oades, Patrick; Royal Devon and Exeter Healthcare Foundation NHS } \\
\text { Trust, Paediatric Unit } \\
\text { Armstrong, Neil; University of Exeter, Children's Health and } \\
\text { Exercise Research Centre } \\
\text { Williams, Craig; University of Exeter, Children's Health and Exercise } \\
\text { Research Centre }\end{array}$ \\
\hline Keywords: & $\begin{array}{l}\text { chronic chest diseases, children, exercise testing, recovery, clinical } \\
\text { measure }\end{array}$ \\
\hline
\end{tabular}

\section{s scholarONE" \\ Manuscript Central}




\section{EARLY OXYGEN UPTAKE RECOVERY FOLLOWING EXERCISE TESTING IN CHILDREN WITH CHRONIC CHEST DISEASES}

D. Stevens MSc, ${ }^{1}$ P.J. Oades FRCPCH, ${ }^{2}$ N. Armstrong D.Sc, ${ }^{1}$ and C.A. Williams Ph.D. ${ }^{1}$

${ }^{1}$ Children's Health and Exercise Research Centre, School of Sport and Health Sciences, University of Exeter, Exeter, Devon, UK. ${ }^{2}$ Royal Devon and Exeter NHS Foundation Trust Hospital, Exeter, Devon, UK.

The study was supported by the School of Sport and Health Sciences, University of Exeter, and the Royal Devon and Exeter NHS Foundation Trust Hospital.

Correspondence to: Craig A. Williams, Ph.D., Children's Health and Exercise, Research Centre, School of Sport and Health Sciences, University of Exeter, St. Luke's Campus, Heavitree Road, Exeter, UK. EX1 2LU

Tel: +44 (0) 1392 264890; Fax: +44 (0) 1392264726

Email: c.a.williams@exeter.ac.uk

Running head: RECOVERY FOLLOWING EXERCISE IN CHRONIC CHEST DISEASES 
Summary. The value of exercise testing as a prognostic measure of disease severity in patients with chronic chest diseases (CCD) is becoming increasingly recognised. The aim of this study was to investigate changes in oxygen uptake $\left(\dot{\mathrm{V}} \mathrm{O}_{2}\right)$ during early recovery following maximal cardiopulmonary exercise testing (CPXT) in relation to functional capacity and markers of disease severity. Twenty-seven children with CCD (age $12.7 \pm 3.1 \mathrm{y} ; 17$ female) [19 children with Cystic fibrosis (CF) (age $13.4 \pm 3.1 \mathrm{y} ; 10$ female) and 8 with other stable non-CF chest diseases (NON-CF) (age $11.1 \pm 2.2 \mathrm{y} ; 7$ female)] and 27 healthy controls (age $13.2 \pm 3.3 \mathrm{y} ; 17$ female) underwent CPXT on a cycle ergometer. On-line respiratory gas analysis measured $\dot{\mathrm{V}} \mathrm{O}_{2}$ before and during CPXT to peak $\dot{\mathrm{VO}}_{2}\left(\dot{\mathrm{VO}}_{2}\right.$ peak $)$, and during the first 10 min of recovery. Early $\dot{\mathrm{VO}}_{2}$ recovery was quantified by the time (s) to reach $50 \%$ of the $\dot{\mathrm{VO}}_{2}$ peak value. Early $\dot{\mathrm{VO}}_{2}$ recovery was correlated against spirometry [forced expiratory volume in $1 \mathrm{~s}\left(\mathrm{FEV}_{1}\right)$ and forced expiratory flow between 25 to $75 \%$ of the forced vital capacity $\left.\left(\mathrm{FEF}_{25-75}\right)\right]$ and aerobic fitness $\left(\dot{\mathrm{VO}}_{2 \text { peak }}\right)$ as a measure of functional capacity. Disease severity was graded in the CF patients by the Shwachman score (SS). Compared to controls, children with CCD demonstrated a significantly reduced $\dot{\mathrm{VO}}_{2 \text { peak }}(P=0.011), \mathrm{FEV}_{1}(P=0.000), \mathrm{FEF}_{25-75}(P=0.000)$, and a significantly prolonged early $\dot{\mathrm{VO}}_{2}$ recovery $(P=0.024)$. In the $\mathrm{CF}$ patients the SS was significantly correlated with early $\dot{\mathrm{VO}}_{2}$ recovery $(r=-0.63, P=0.004)$, $\mathrm{FEV}_{1}(r=0.72, P=0.001)$ and $\mathrm{FEF}_{25-75}(r=0.57, P=0.011)$. In the children with $\mathrm{CCD}, \mathrm{FEV}_{1}, \mathrm{FEF}_{25-75}$ and $\mathrm{BMI}$ were not significantly correlated with $\dot{\mathrm{VO}}_{2}$ peak or early $\dot{\mathrm{VO}}_{2}$ recovery, indicating that lung function does not necessarily reflect aerobic fitness and the ability to recover from exercise in these patients. A significant relationship was found between $\dot{\mathrm{VO}}_{2}$ peak and early $\dot{\mathrm{V}}{ }_{2}$ recovery $(r=-0.39, P=$ 
0.044) in the children with $\mathrm{CCD}$, showing that a greater aerobic fitness corresponded with a faster recovery.

Key words: chronic chest diseases, children, exercise testing, recovery, clinical measure 


\section{INTRODUCTION}

Exercise testing is a valuable tool for monitoring the physiological impact of chronic chest diseases (CCD). ${ }^{1}$ Exercise testing is incorporated in some paediatric respiratory centres as part of an annual assessment of children with Cystic fibrosis (CF), ${ }^{2}$ based on evidence demonstrating that aerobic and anaerobic exercise are limited, ${ }^{3}$ and that this limitation is related to survival. ${ }^{4}$ Peak oxygen uptake $\left(\mathrm{V}_{2}\right.$ peak $)$ during maximal cardiopulmonary exercise testing (CPXT) is considered the 'gold standard' measure for assessing aerobic fitness, ${ }^{1}$ and is an important measure for well-being and prognosis in CF. ${ }^{4,5}$ Lung function measured by spirometry, ${ }^{6}$ and $\dot{\mathrm{V}} \mathrm{O}_{2 \text { peak }}$ measured during $\mathrm{CPXT}^{7}$ are commonly measured to assess functional capacity and disease severity in patients with $\mathrm{CF}$. Limited data exists, however, regarding recovery parameters following exercise testing in children with CCD.

During early recovery from exercise, phosphocreatine $(\mathrm{PCr})$ levels are inversely proportional to the rate of oxygen uptake $\left(\dot{\mathrm{VO}}_{2}\right)$, and dependent on the transport to and utilisation of oxygen $\left(\mathrm{O}_{2}\right)$ within contracting muscle. ${ }^{8,9}$ The importance of $\mathrm{O}_{2}$ in the resynthesis of PCr has been previously reported. ${ }^{10-13}$ Anaerobic glycolysis ceases at the termination of peak exercise, and oxidative phosphorylation provides the ATP required for $\mathrm{PCr}$ recovery. ${ }^{14}$ In cardiac diseases where the transportation and utilisation of $\mathrm{O}_{2}$ in the contracting muscle is adversely affected, $\mathrm{PCr}$ recovery time has been reported to be prolonged following exercise, ${ }^{15-18}$ whereas, a faster $\mathrm{PCr}$ recovery time has been demonstrated in healthy trained individuals. ${ }^{19}$ The rate of $\mathrm{PCr}$ resynthesis during recovery from exercise is, therefore, a reflection of oxidative capacity, and can be inferred from $\dot{\mathrm{VO}}_{2}$ measurements in children. ${ }^{20}$ 
We hypothesised that $\mathrm{PCr}$ resynthesis, as reflected by the $\dot{\mathrm{VO}}_{2}$ during early recovery from CPXT, is an index of the efficiency of maximal oxidative rate, and 1) will be prolonged in children with CCD compared to healthy controls, and 2) serve as an index of disease severity. Therefore, the aims of the study are to assess the $\mathrm{V}_{2}$ responses during early recovery from CPXT in children with $\mathrm{CCD}$ and healthy controls, and explore the relationships with markers of functional capacity and disease severity in children with CCD. 


\section{MATERIALS AND METHODS}

\section{Participants}

Twenty-seven children with CCD participated in the study (age $12.7 \pm 3.1 \mathrm{y} ; 17$ female). For further analysis the children with CCD were divided into two diagnostic groups. One group consisted of 19 children with CF (age $13.4 \pm 3.1 \mathrm{y} ; 10$ female), and the other group consisted of 8 children with other stable non-CF chest diseases (NONCF) (age $11.1 \pm 2.2 \mathrm{y} ; 7$ female) [5 Non-CF bronchiectasis; 2 Primary ciliary dyskinesia; 1 Post-adenoviral obliterative bronchiolitis]. Twenty-seven healthy controls (age $13.2 \pm 3.3 \mathrm{y} ; 17$ female) free from any musculoskeletal, cardiovascular and pulmonary diseases that would compromise exercise performance were recruited from local schools and colleges in Devon, U.K. The controls were individually pair matched to the children with CCD for stature, body mass and pubertal maturity.

All participants volunteered for the study and written informed consent and assent was obtained from parents and participants, respectively. All children with CCD attended the outpatient clinic of the Royal Devon and Exeter NHS Foundation Trust Hospital. All children with CCD were clinically stable at the time of CPXT, with no symptomatic deterioration over the preceding month. None had musculoskeletal conditions that would compromise exercise performance. Diagnosis of CF was based on clinical features supported by an abnormal sweat test (sweat chloride $>60 \mathrm{mmol} \cdot \mathrm{L}$ ) and in 17/19 diagnostic genotyping. Pubertal staging was assessed during routine outpatient clinic assessment by a trained nurse and classified as pre-, peri- and postpubertal. ${ }^{21}$ The study was approved by the NHS Local Research Ethics Committee. 


\section{Maximal Cardiopulmonary Exercise Testing (CPXT)}

Infection control measures to prevent cross-infection were followed. Children with CCD were segregated in both waiting areas and testing places. Both equipment and the testing environment were cleaned using appropriate bacteriocidal wipes and solutions after each use.

Before CPXT all participants were instructed not to consume food or caffeine $2 \mathrm{hrs}$ before and wear light comfortable clothes suitable for exercising on a cycle. All participants were also asked not to perform any strenuous exercise during $48 \mathrm{hrs}$ prior to the test time. Maximal cardiopulmonary exercise testing was performed on a cycle ergometer (Excaliber Sport; Lode, Groningen, The Netherlands) using a ramp protocol, commencing with unloaded pedalling for $2 \mathrm{~min}$ and then $10 \mathrm{~W}$ increases were made incrementally every min. All participants pedalled at a cadence of $70 \pm 5$ rpm and encouraged to continue until voluntary exhaustion. Peak oxygen uptake was determined by satisfying the following criteria; a respiratory exchange ratio $>1.06$; heart rate $>95 \%$ age related predicted maximum; scores of $8-10$ after exercise on a children's effort rating table (CERT); and clinically observed signs of facial flushing, sweating and tachypnoea.

An on-line metabolic gas analyser (Cortex Metalyzer; Cortex Medical, Leipzig, Germany) measured $\dot{\mathrm{V}} \mathrm{O}_{2}$ continuously. The system was calibrated with standard gas of known concentration before each test. Gas measurements were collected in the upright position before and during CPXT to $\dot{\mathrm{VO}}_{2}$ peak, and during the first 10 min of recovery using a $10 \mathrm{~s}$ moving average. Peak oxygen uptake was calculated as the highest recorded 30 s stationary average value during the CPXT. 


\title{
Assessment of Functional Capacity
}

Peak oxygen uptake and lung function were used as markers of functional capacity. Peak oxygen uptake was used as a measure of aerobic fitness and expressed relative to body mass $\left(\mathrm{mL}^{-1} \mathrm{~kg}^{-1} \mathrm{~min}^{-1}\right)$. Lung function was assessed by forced expiratory volume in $1 \mathrm{~s}\left(\mathrm{FEV}_{1}\right)$, and forced expiratory flow between 25 to $75 \%$ of the forced vital capacity $\left(\mathrm{FEF}_{25-75}\right)$. All lung function measurements were expressed as \% predicted, using appropriate reference data. ${ }^{22}$ Each participant's lung function was measured before the start of the CPXT. The forced expiratory manoeuvre was performed as recommended by the British Thoracic Society (1994) guidelines for the measurement of respiratory function, ${ }^{23}$ recording the best of three consistent exhalations, using an electronic spirometer (Microloop ML3535; Numed, Sheffield, UK).

\author{
Assessment of Early $\dot{\mathrm{V}}_{2}$ Recovery \\ Early $\dot{\mathrm{VO}}_{2}$ recovery time was quantified by the time in seconds (s) from the cessation

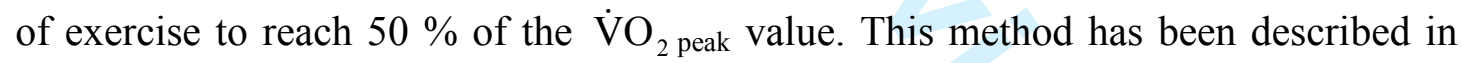 \\ previous studies to assess early $\dot{\mathrm{VO}}_{2}$ recovery in patients with cardiac diseases. ${ }^{24-26}$
}

\begin{abstract}
Assessment of Disease Severity for the Cystic Fibrosis Patients
The Shwachman score (SS) was used to grade disease severity in the CF patients, and was recorded prior to CPXT by the patient's clinician. The SS scores four separate aspects of the disease profile, general activity, physical examination, nutritional status and chest radiographic findings, using the most recent routine annual review chest $\mathrm{x}$ ray. Each disease profile is given an equal weighting of 25 points. A total of 100 points represents a perfect score of health. ${ }^{27}$
\end{abstract}




\section{Data Analysis}

Data were analysed using the Statistical Package for the Social Sciences (SPSS; version 11.0, Chicago, IL). The independent $t$-test was used for the comparison of the anthropometric and physiological data between children with CCD and controls. The Pearson product moment correlation was used to assess the association between $\dot{\mathrm{VO}}_{2}$ indexes and parameters of functional capacity and disease severity. Statistical significance was set a priori at $P<0.05$. 


\section{RESULTS}

The anthropometric data in Table 1 shows no significant differences in stature, body mass, BMI and pubertal maturity between the children with CCD and controls. The lung function data (Table 1) showed when compared to controls, children with CCD demonstrated significantly reduced $\mathrm{FEV}_{1}(P=0.000)$, FVC $(P=0.004)$, PEF $(P=$ 0.003), and $\mathrm{FEF}_{25-75}(P=0.000)$. Data from the CPXT (Table 2) showed that compared to controls the children with $\mathrm{CCD}$ had a significantly lower $\dot{\mathrm{V}}_{2}$ peak $(P=$ $0.011)$ and a significantly prolonged early $\dot{\mathrm{VO}}_{2}$ recovery $(P=0.024)$. Other CPXT data such as maximum workload $\left(\mathrm{W}_{\max }\right)$ was significantly lower $(P=0.009)$ in children with CCD compared to controls. Maximum heart rate $\left(\mathrm{HR}_{\max }\right)$ did not differ significantly between children with CCD and controls during CPXT (Table 2).

The correlation data (Table $3 \mathrm{a}$ ) showed in the children with $\mathrm{CCD}, \mathrm{FEV}_{1}, \mathrm{FEF}_{25-75}$ and BMI were not significantly correlated with $\dot{\mathrm{V}}_{2}$ peak or early $\dot{\mathrm{V}} \mathrm{O}_{2}$ recovery. A significant negative relationship between $\dot{\mathrm{VO}}_{2}$ peak and early $\dot{\mathrm{VO}}_{2}$ recovery $(r=$ $0.39, P=0.044$ ), however, was found in the children with CCD (Table 3a and Figure 1). Sub-group analysis within the children with CCD revealed, in the CF patients a significant negative correlation between the SS and early $\dot{\mathrm{VO}}_{2}$ recovery $(r=-0.63, P$ $=0.004)$ (Table $3 \mathrm{a}$ and Figure 2), and significant correlations were also shown between the SS and $\mathrm{FEV}_{1}(r=0.72, P=0.001)($ Table $3 \mathrm{a}$ and Figure 3$)$, and $\mathrm{FEF}_{25-75}$ ( $r=0.57, P=0.011$ ) (Table 3a). No significant correlation, however, was found between the SS and $\dot{\mathrm{VO}}_{2}$ peak in the $\mathrm{CF}$ patients (Table 3a). Between the $\mathrm{CF}$ and NON-CF patients no significant differences in $\dot{\mathrm{V}} \mathrm{O}_{2}$ peak $(P=0.715)$ and early $\dot{\mathrm{VO}}_{2}$ recovery $(P=0.755)$ were shown, despite the NON-CF patients demonstrating a 
significantly reduced $\mathrm{FEV}_{1}(P=0.044)$ compared to the $\mathrm{CF}$ patients. Table $3 \mathrm{~b}$ shows the correlational relationships for the healthy control group, only BMI was found to be significantly correlated to recovery $(r=0.48, P=0.011)$. 


\section{DISCUSSION}

The present study found that compared to controls, children with CCD demonstrated a significantly reduced $\dot{\mathrm{V}}{ }_{2}$ peak and prolonged early $\dot{\mathrm{V}} \mathrm{O}_{2}$ recovery following CPXT. The metabolic cost of exercise results from both the performance of external work, and the demands of the $\mathrm{O}_{2}$ transportation system itself. This includes the work performed by the muscles of respiration and the enduring metabolic demand to restore homeostasis during recovery. ${ }^{28}$ The rate of $\dot{\mathrm{VO}}_{2}$ during early recovery from exercise in children with CCD will be influenced by many disease factors. For example, as disease progresses there is an increase in dead space, ${ }^{29}$ that necessitates an increase in total ventilation in order to keep alveolar ventilation constant. ${ }^{30,31}$ Airway obstruction and air trapping would also reduce the rate of elimination of excess carbon dioxide formed during exercise, prolonging tachypnoea, which itself would increase the metabolic demand and which contributes to fatigue. ${ }^{32}$ Delayed elimination of carbon dioxide would also impair the ability to compensate for alterations in acid-based status. ${ }^{33}$ Furthermore, in patients with $\mathrm{CF}$ the correlation between thin section computed tomographic (CT) findings of lung parenchymal damage and exercise limitation is stronger than that between spirometry results, or BMI and exercise limitation. ${ }^{34}$ The CF genotype has also been reported to be related to exercise tolerance. $^{35}$

The lung function data from the present study showed that $\mathrm{FEV}_{1}, \mathrm{FVC}, \mathrm{PEF}$ and $\mathrm{FEF}_{25-75}$ were all significantly reduced in children with $\mathrm{CCD}$ compared to controls. Forced expiratory volume in $1 \mathrm{~s}, \mathrm{FEF}_{25-75}$ and $\mathrm{BMI}$ in the children with $\mathrm{CCD}$, however, were not significantly correlated with $\dot{\mathrm{VO}}_{2}$ peak or early $\dot{\mathrm{V}} \mathrm{O}_{2}$ recovery. Furthermore, the study showed that despite a significantly reduced $\mathrm{FEV}_{1}$ in the NON- 
$\mathrm{CF}$ patients compared to the $\mathrm{CF}$ patients, $\dot{\mathrm{VO}}_{2}$ peak and early $\dot{\mathrm{VO}}_{2}$ recovery were not significantly different between the two patient groups. These findings demonstrate, therefore, that exercise performance was similar between the NON-CF and CF patients, despite poorer lung function in the NON-CF patients. These finding may emphasise the physiological differences between the static nature of lung function testing and the dynamic nature of the cardiopulmonary system when exercising. It may also infer, however, the physiological differences between children with CF and other $\mathrm{CCD}$, especially in regard to recent work which found that $\mathrm{CF}$ patients demonstrated reduced oxidative work efficiency in the skeletal muscle. ${ }^{36}$

Contrary to previous studies which have reported that reduced $\mathrm{FEV}_{1}$ is associated with lower $\dot{\mathrm{VO}}_{2}$ peak, ${ }^{29,37-41}$ a non-significant relationship between lung function and $\dot{\mathrm{V}} \mathrm{O}_{2 \text { peak }}$ in the children with $\mathrm{CCD}$ in the present study may provide further support to work which has reported that reduced aerobic performance is related to intrinsic abnormalities of skeletal muscle function. ${ }^{36,42-44}$ Furthermore, a recent study reported that $\dot{\mathrm{V}} \mathrm{O}_{2 \text { peak }}$ and exercise duration during CPXT was not affected in patients with mild CF using added dead space, suggesting the CPXT is not limited by respiratory factors. ${ }^{45}$ Moser et al. (2000) also found no significant correlations between variables reflecting exercise performance (e.g., $\dot{\mathrm{VO}}_{2}$ peak) and lung function measurements (e.g., FEV $_{1}$ ) in children with CF. ${ }^{43}$ This finding is also supported by Edwards et al. (2004), who reported no relationships between variables measured during exercise testing and lung function. ${ }^{46}$ Peak oxygen uptake and early $\dot{\mathrm{VO}}_{2}$ recovery, however, were significantly related; indicating the greater the aerobic fitness of the patient the faster the rate of recovery. This relationship although significant, however, is still quite 
weak $(r=-0.39, P=0.044)$, and therefore, may indicate that the $\dot{\mathrm{VO}} \mathrm{O}_{2}$ recovery can not be explained predominantly by the $\dot{\mathrm{V}} \mathrm{O}_{2}$ peak. However, the finding that $\dot{\mathrm{V}} \mathrm{O}_{2}$ peak and early $\dot{\mathrm{V}} \mathrm{O}_{2}$ recovery were not significantly correlated for the healthy control group accentuates the relative importance of aerobic fitness and recovery and their impact on children with CCD.

In children with CF a significant relationship between early $\dot{\mathrm{VO}}_{2}$ recovery and the SS was found. Correlations between structural abnormalities of the lung scored on thin section $\mathrm{CT}$ images and exercise performance have been reported in patients with $\mathrm{CF}$, and these relationships are stronger than that between spirometry results, or BMI and exercise limitation, ${ }^{34}$ and may explain the relationship found in the present study. Forced expiratory volume in $1 \mathrm{~s}$ and $\mathrm{FEF}_{25-75}$ in the children with $\mathrm{CF}$ were also significantly related to the SS, confirming previous reports that lung function is correlated with disease severity and survival in CF patients. ${ }^{6,47,48}$ No significant relationship between $\dot{\mathrm{VO}}_{2}$ peak and the SS in the CF patients was found in the present study. The $\dot{\mathrm{VO}}_{2}$ peak values for children with $\mathrm{CF}$ in this study are similar to published values of aerobic fitness for young CF patients of a similar age range. ${ }^{43,49,50} \mathrm{~A}$ significant correlation between $\dot{\mathrm{VO}}_{2}$ peak and SS has been previously reported in adults with CF, ${ }^{51}$ but not in children. The disease severity of the adult CF patients was greater than in the present study $\left(71 \pm 14\right.$ versus $80 \pm 12$, respectively) and $\dot{\mathrm{V}} \mathrm{O}_{2 \text { peak }}$ was lower $\left(25 \pm 7\right.$ versus $35 \pm 8 \mathrm{mLkg}^{-1} \mathrm{~min}^{-1}$, respectively), which may have increased the likelihood of finding a significant relationship due to a greater heterogeneity of the correlated variables. 
In conclusion, children with CCD in the present study had mild to moderate disease as interpreted by their lung function, and showed a reduced $\dot{\mathrm{VO}}_{2}$ peak and prolonged early $\dot{\mathrm{V}} \mathrm{O}_{2}$ recovery compared to a control group. The prolonged recovery may be an indication of reduced oxidative capacity for $\mathrm{PCr}$ resynthesis, attributed to impaired $\mathrm{O}_{2}$ transportation and utilisation in the contracting muscle. Indeed, the present study showed that early $\dot{\mathrm{VO}}_{2}$ recovery was significantly related to the SS in children with $\mathrm{CF}$, indicating that early $\dot{\mathrm{VO}}_{2}$ recovery is prolonged with increased disease severity. Lung function was not significantly related to $\dot{\mathrm{V}} \mathrm{O}_{2}$ peak and early $\dot{\mathrm{VO}}_{2}$ recovery, and therefore may not accurately reflect the patient's ability to exercise and recover. Disease in CF can progress significantly, as shown on thoracic high resolution CT scanning, despite lung function stability. ${ }^{52}$ Exercise testing can therefore help to provide useful additional information about functional limitations and trends over time. ${ }^{53}$ A recent study reported that higher aerobic fitness despite poor lung function is associated with a better prognosis. ${ }^{49}$ The links between more detailed measures of exercise performance including recovery parameters, disease severity and quality of life deserve more attention and warrant further investigation. 


\section{ACKNOWLEDGMENTS}

The authors would like to thank the staff at the Paediatric Unit (Bramble Ward), Royal Devon and Exeter NHS Foundation Trust Hospital, for their help and assistance, and to the technical staff at the School of Sport and Health Sciences, University of Exeter, for their support. Finally, the authors would like to express their appreciation to the children who participated in this study. The study was supported by funds from the School of Sport and Health Sciences, University of Exeter, and the Research and Development department, Royal Devon and Exeter NHS Foundation Trust Hospital. The authors declare that there are no conflicts of interest in this study. 


\section{REFERENCES}

1. Palange P, Ward SA, Carlsen KH, Casaburi R, Gallagher CG, Gosselink R, O'Donnell DE, Puente-Maestu L, Schols AM, Singh S, Whipp BJ. Recommendations on the use of exercise testing in clinical practice. Eur Respir J 2007;29(1):185-209.

2. Orenstein DM. Exercise testing in cystic fibrosis. Pediatr Pulmonol 1998;25(4):223-225.

3. Shah AR, Gozal D, Keens TG. Determinants of aerobic and anaerobic exercise performance in cystic fibrosis. Am J Respir Crit Care Med 1998;157(4 Pt 1):1145-1150.

4. Nixon PA, Orenstein DM, Kelsey SF, Doershuk CF. The prognostic value of exercise testing in patients with cystic fibrosis. New England Journal of Medicine 1992;327(25):1785-1788.

5. Orenstein DM, Nixon PA, Ross EA, Kaplan RM. The quality of well-being in cystic fibrosis. Chest 1989;95(2):344-347.

6. Kerem E, Reisman J, Corey M, Canny GJ, Levison H. Prediction of mortality in patients with cystic fibrosis. N Engl J Med 1992;326(18):1187-1191.

7. Webb AK, Dodd ME, Moorcroft J. Exercise and cystic fibrosis. J R Soc Med 1995;88 Suppl 25:30-36.

8. Mahler M. First-order kinetics of muscle oxygen consumption, and an equivalent proportionality between QO2 and phosphorylcreatine level. Implications for the control of respiration. J Gen Physiol 1985;86(1):135-165.

9. Meyer RA. A linear model of muscle respiration explains monoexponential phosphocreatine changes. Am J Physiol 1988;254(4 Pt 1):C548-553.

10. Harris RC, Edwards RH, Hultman E, Nordesjo LO, Nylind B, Sahlin K. The time course of phosphorylcreatine resynthesis during recovery of the quadriceps muscle in man. Pflugers Arch 1976;367(2):137-142.

11. Sahlin K, Harris RC, Hultman E. Resynthesis of creatine phosphate in human muscle after exercise in relation to intramuscular $\mathrm{pH}$ and availability of oxygen. Scand J Clin Lab Invest 1979;39(6):551-558.

12. Taylor DJ, Bore PJ, Styles P, Gadian DG, Radda GK. Bioenergetics of intact human muscle. A 31P nuclear magnetic resonance study. Mol Biol Med 1983;1(1):77-94.

13. Quistorff B, Johansen L, Sahlin K. Absence of phosphocreatine resynthesis in human calf muscle during ischaemic recovery. Biochem J 1993;291 ( Pt 3):681-686. 
14. McMahon S, Jenkins D. Factors affecting the rate of phosphocreatine resynthesis following intense exercise. Sports Med 2002;32(12):761-784.

15. Massie BM, Conway M, Yonge R, Frostick S, Sleight P, Ledingham J, Radda G, Rajagopalan B. 31P nuclear magnetic resonance evidence of abnormal skeletal muscle metabolism in patients with congestive heart failure. Am J Cardiol 1987;60(4):309-315.

16. Mancini DM, Ferraro N, Tuchler M, Chance B, Wilson JR. Detection of abnormal calf muscle metabolism in patients with heart failure using phosphorus-31 nuclear magnetic resonance. Am J Cardiol 1988;62(17):12341240 .

17. Chati Z, Zannad F, Robin-Lherbier B, Escanye JM, Jeandel C, Robert J, Aliot E. Contribution of specific skeletal muscle metabolic abnormalities to limitation of exercise capacity in patients with chronic heart failure: a phosphorus 31 nuclear magnetic resonance study. Am Heart J 1994;128(4):781-792.

18. Belardinelli R, Barstow TJ, Nguyen P, Wasserman K. Skeletal muscle oxygenation and oxygen uptake kinetics following constant work rate exercise in chronic congestive heart failure. Am J Cardiol 1997;80(10):1319-1324.

19. McCully KK, Vandenborne K, DeMeirleir K, Posner JD, Leigh JS, Jr. Muscle metabolism in track athletes, using 31P magnetic resonance spectroscopy. Can J Physiol Pharmacol 1992;70(10):1353-1359.

20. Barker AR, Welsman JR, Fulford J, Welford D, Williams CA, Armstrong N. Muscle phosphocreatine and pulmonary oxygen uptake kinetics in children at the onset and offset of moderate intensity exercise. Eur J Appl Physiol 2008;102(6):727-738.

21. Tanner JM. Growth at Adolescence, 2nd Edition. Oxford: Blackwell Scientific Publications; 1962.

22. Zapletal A, Samanek M, Paul T. Lung function in children and adolescents. Methods, reference values. In: Zapletal A, editor. Progress in Respiration Research. Volume 22; 1987. p 114-116.

23. Guidelines for the measurement of respiratory function. Recommendations of the British Thoracic Society and the Association of Respiratory Technicians and Physiologists. Respir Med 1994;88(3):165-194.

24. Nanas S, Nanas J, Kassiotis C, Nikolaou C, Tsagalou E, Sakellariou D, Terovitis I, Papazachou O, Drakos S, Papamichalopoulos A, Roussos C. Early recovery of oxygen kinetics after submaximal exercise test predicts functional capacity in patients with chronic heart failure. Eur J Heart Fail 2001;3(6):685692. 
25. Tanabe Y, Takahashi M, Hosaka Y, Ito M, Ito E, Suzuki K. Prolonged recovery of cardiac output after maximal exercise in patients with chronic heart failure. J Am Coll Cardiol 2000;35(5):1228-1236.

26. Cohen-Solal A, Laperche T, Morvan D, Geneves M, Caviezel B, Gourgon R. Prolonged kinetics of recovery of oxygen consumption after maximal graded exercise in patients with chronic heart failure. Analysis with gas exchange measurements and NMR spectroscopy. Circulation 1995;91(12):2924-2932.

27. Shwachman H, Kulczycki LL. Long-term study of one hundred five patients with cystic fibrosis; studies made over a five- to fourteen-year period. AMA J Dis Child 1958;96(1):6-15.

28. Gaesser GA, Brooks GA. Metabolic bases of excess post-exercise oxygen consumption: a review. Med Sci Sports Exerc 1984;16(1):29-43.

29. Godfrey S, Mearns M. Pulmonary function and response to exercise in cystic fibrosis. Archives of Disease in Childhood 1971;46(246):144-151.

30. Hirsch JA, Zhang SP, Rudnick MP, Cerny FJ, Cropp GJ. Resting oxygen consumption and ventilation in cystic fibrosis. Pediatr Pulmonol 1989;6(1):1926.

31. Coates AL, Canny G, Zinman R, Grisdale R, Desmond K, Roumeliotis D, Levison $\mathrm{H}$. The effects of chronic airflow limitation, increased dead space, and the pattern of ventilation on gas exchange during maximal exercise in advanced cystic fibrosis. Am Rev Respir Dis 1988;138(6):1524-1531.

32. Gallagher CG, Younes $M$. Breathing pattern during and after maximal exercise in patients with chronic obstructive lung disease, interstitial lung disease, and cardiac disease, and in normal subjects. Am Rev Respir Dis 1986;133(4):581-586.

33. Chonan T, elHefnawy AM, Simonetti OP, Cherniack NS. Rate of elimination of excess CO2 in humans. Respir Physiol 1988;73(3):379-394.

34. Dodd JD, Barry SC, Barry RB, Gallagher CG, Skehan SJ, Masterson JB. Thin-section CT in patients with cystic fibrosis: correlation with peak exercise capacity and body mass index. Radiology 2006;240(1):236-245.

35. Selvadurai HC, McKay KO, Blimkie CJ, Cooper PJ, Mellis CM, Van Asperen $\mathrm{PP}$. The relationship between genotype and exercise tolerance in children with cystic fibrosis. Am J Respir Crit Care Med 2002;165(6):762-765.

36. de Meer K, Jeneson JA, Gulmans VA, van der Laag J, Berger R. Efficiency of oxidative work performance of skeletal muscle in patients with cystic fibrosis. Thorax 1995;50(9):980-983.

37. Cerny FJ, Pullano TP, Cropp GJ. Cardiorespiratory adaptations to exercise in cystic fibrosis. Am Rev Respir Dis 1982;126(2):217-220. 
38. Cropp GJ, Pullano TP, Cerny FJ, Nathanson IT. Exercise tolerance and cardiorespiratory adjustments at peak work capacity in cystic fibrosis. Am Rev Respir Dis 1982;126(2):211-216.

39. Marcotte JE, Canny GJ, Grisdale R, Desmond K, Corey M, Zinman R, Levison $\mathrm{H}$, Coates AL. Effects of nutritional status on exercise performance in advanced cystic fibrosis. Chest 1986;90(3):375-379.

40. Marcotte JE, Grisdale RK, Levison H, Coates AL, Canny GJ. Multiple factors limit exercise capacity in cystic fibrosis. Pediatr Pulmonol 1986;2(5):274-281.

41. Lands LC, Heigenhauser GJ, Jones NL. Analysis of factors limiting maximal exercise performance in cystic fibrosis. Clin Sci (Lond) 1992;83(4):391-397.

42. Kusenbach G, Wieching R, Barker M, Hoffmann U, Essfeld D. Effects of hyperoxia on oxygen uptake kinetics in cystic fibrosis patients as determined by pseudo-random binary sequence exercise. Eur J Appl Physiol Occup Physiol 1999;79(2):192-196.

43. Moser C, Tirakitsoontorn P, Nussbaum E, Newcomb R, Cooper DM. Muscle size and cardiorespiratory response to exercise in cystic fibrosis. American Journal of Respiratory and Critical Care Medicine 2000;162(5):1823-1827.

44. Selvadurai HC, Allen J, Sachinwalla T, Macauley J, Blimkie CJ, Van Asperen PP. Muscle function and resting energy expenditure in female athletes with cystic fibrosis. Am J Respir Crit Care Med 2003;168(12):1476-1480.

45. Dodd JD, Barry SC, Gallagher CG. Respiratory factors do not limit maximal symptom-limited exercise in patients with mild cystic fibrosis lung disease. Respir Physiol Neurobiol 2006;152(2):176-185.

46. Edwards EA, Narang I, Li A, Hansell DM, Rosenthal M, Bush A. HRCT lung abnormalities are not a surrogate for exercise limitation in bronchiectasis. Eur Respir J 2004;24(4):538-544.

47. Huang NN, Schidlow DV, Szatrowski TH, Palmer J, Laraya-Cuasay LR, Yeung W, Hardy K, Quitell L, Fiel S. Clinical features, survival rate, and prognostic factors in young adults with cystic fibrosis. Am $\mathrm{J}$ Med 1987;82(5):871-879.

48. Sharples L, Hathaway T, Dennis C, Caine N, Higenbottam T, Wallwork J. Prognosis of patients with cystic fibrosis awaiting heart and lung transplantation. J Heart Lung Transplant 1993;12(4):669-674.

49. Pianosi P, Leblanc J, Almudevar A. Peak oxygen uptake and mortality in children with cystic fibrosis. Thorax 2005;60(1):50-54.

50. Javadpour SM, Selvadurai H, Wilkes DL, Schneiderman-Walker J, Coates AL. Does carbon dioxide retention during exercise predict a more rapid 
decline in FEV1 in cystic fibrosis? Archives of Disease in Childhood 2005;90(8):792-795.

51. Pouliou E, Nanas S, Papamichalopoulos A, Kyprianou T, Perpati G, Mavrou I, Roussos C. Prolonged oxygen kinetics during early recovery from maximal exercise in adult patients with cystic fibrosis. Chest 2001;119(4):1073-1078.

52. de Jong PA, Nakano Y, Lequin MH, Mayo JR, Woods R, Pare PD, Tiddens HA. Progressive damage on high resolution computed tomography despite stable lung function in cystic fibrosis. Eur Respir J 2004;23(1):93-97.

53. Stevens D, Williams CA. Exercise testing and training with the young Cystic fibrosis patient. Journal of Sports Science and Medicine 2007;6:286-291. 
TABLE 3b - Correlation data for the healthy controls $(n=27)$

\begin{tabular}{|c|c|c|c|c|c|}
\hline & BMI & $\begin{array}{c}\mathrm{FEV}_{1} \\
\text { (\% predicted) }\end{array}$ & $\begin{array}{c}\mathrm{FEF}_{25-75} \\
(\% \text { predicted })\end{array}$ & $\begin{array}{c}\dot{\mathrm{V}} \mathrm{O}_{2 \text { peak }} \\
\left(\mathrm{mLkg}^{-1} \cdot \mathrm{min}^{-1}\right)\end{array}$ & $\begin{array}{l}\text { Early } \dot{\mathrm{VO}}_{2} \\
\text { recovery }(\mathrm{s})\end{array}$ \\
\hline BMI & & $\begin{array}{c}r=0.35 \\
(P=0.072)\end{array}$ & $\begin{array}{c}r=-0.33 \\
(P=0.093)\end{array}$ & $\begin{array}{c}r=-0.25 \\
(P=0.202)\end{array}$ & $\begin{array}{l}r=0.48 * * \\
(P=0.011)\end{array}$ \\
\hline $\begin{array}{c}\mathrm{FEV}_{1} \\
(\% \text { predicted })\end{array}$ & & & $\begin{array}{c}r=0.24 \\
(P=0.224)\end{array}$ & $\begin{aligned} r & =-0.30 \\
(P & =0.129)\end{aligned}$ & $\begin{array}{c}r=0.21 \\
(P=0.284)\end{array}$ \\
\hline $\begin{array}{c}\mathrm{FEF}_{25-75} \\
(\% \text { predicted })\end{array}$ & & & & $\begin{aligned} r & =-0.09 \\
(P & =0.670)\end{aligned}$ & $\begin{aligned} r & =-0.03 \\
(P & =0.892)\end{aligned}$ \\
\hline $\begin{array}{c}\dot{\mathrm{VO}}{ }_{2 \text { peak }} \\
\left(\mathrm{mLkg}^{-1} \cdot \mathrm{min}^{-1}\right)\end{array}$ & & & & & $\begin{aligned} r & =-0.24 \\
(P & =0.219)\end{aligned}$ \\
\hline $\begin{array}{l}\text { Early } \dot{\mathrm{VO}}_{2} \\
\text { recovery (s) }\end{array}$ & & & & & \\
\hline
\end{tabular}

expiratory flow between 25 to $75 \%$ of the forced vital capacity; $\dot{\mathrm{VO}}_{2}$ peak, peak oxygen uptake;

Early $\dot{\mathrm{VO}}_{2}$ recovery, early oxygen uptake recovery. 
FIGURE 1 - The relationship between $\dot{\mathrm{V}} \mathrm{O}_{2}$ peak and early $\dot{\mathrm{V}} \mathrm{O}_{2}$ recovery in the children with $\operatorname{CCD}(\mathrm{n}=27)$

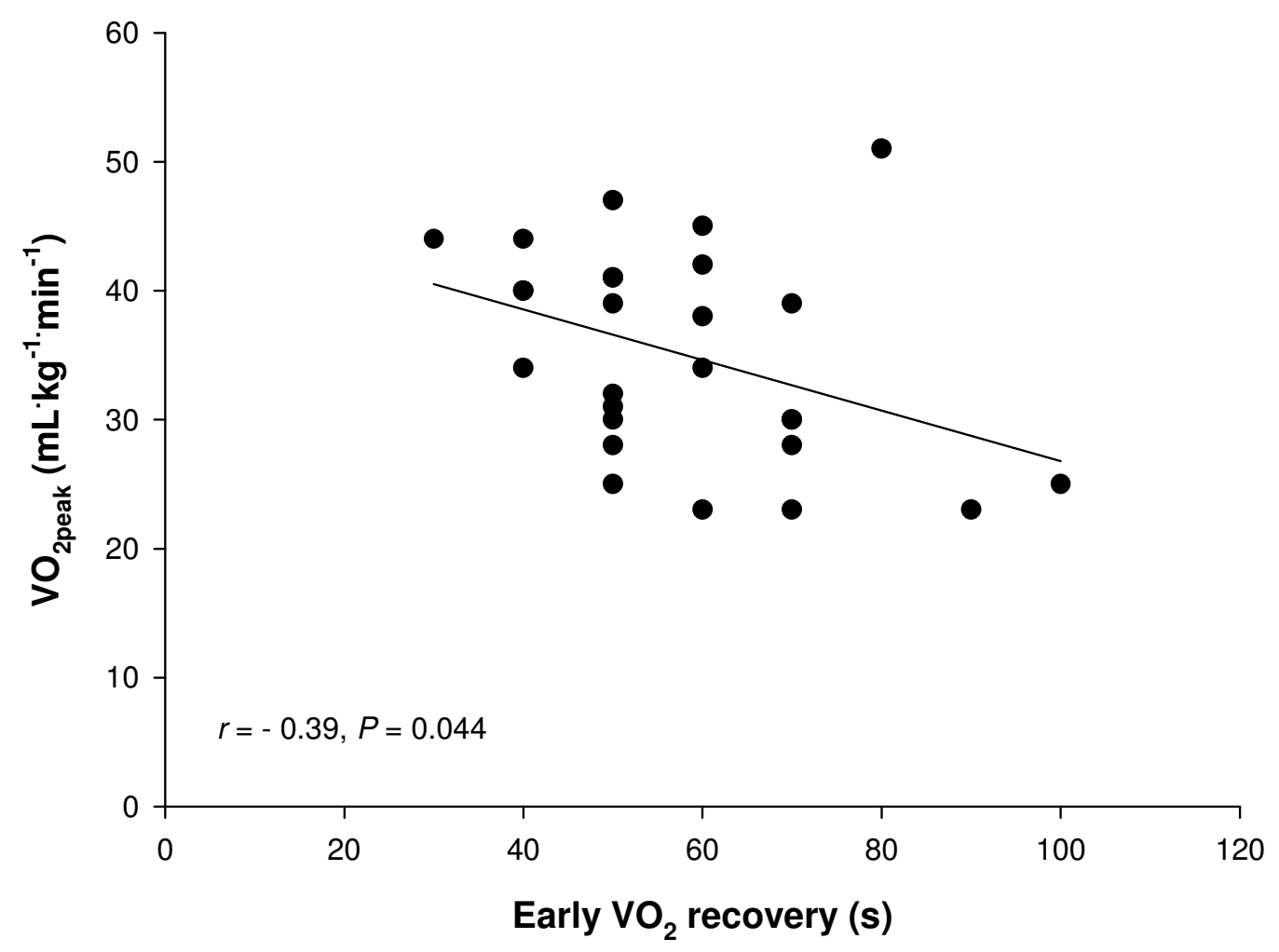

John Wiley \& Sons, Inc. 
FIGURE 2 - The relationship between the Shwachman score and early $\dot{\mathrm{V}}_{2}$ recovery in the $\mathrm{CF}$ patients $(\mathrm{n}=19)$

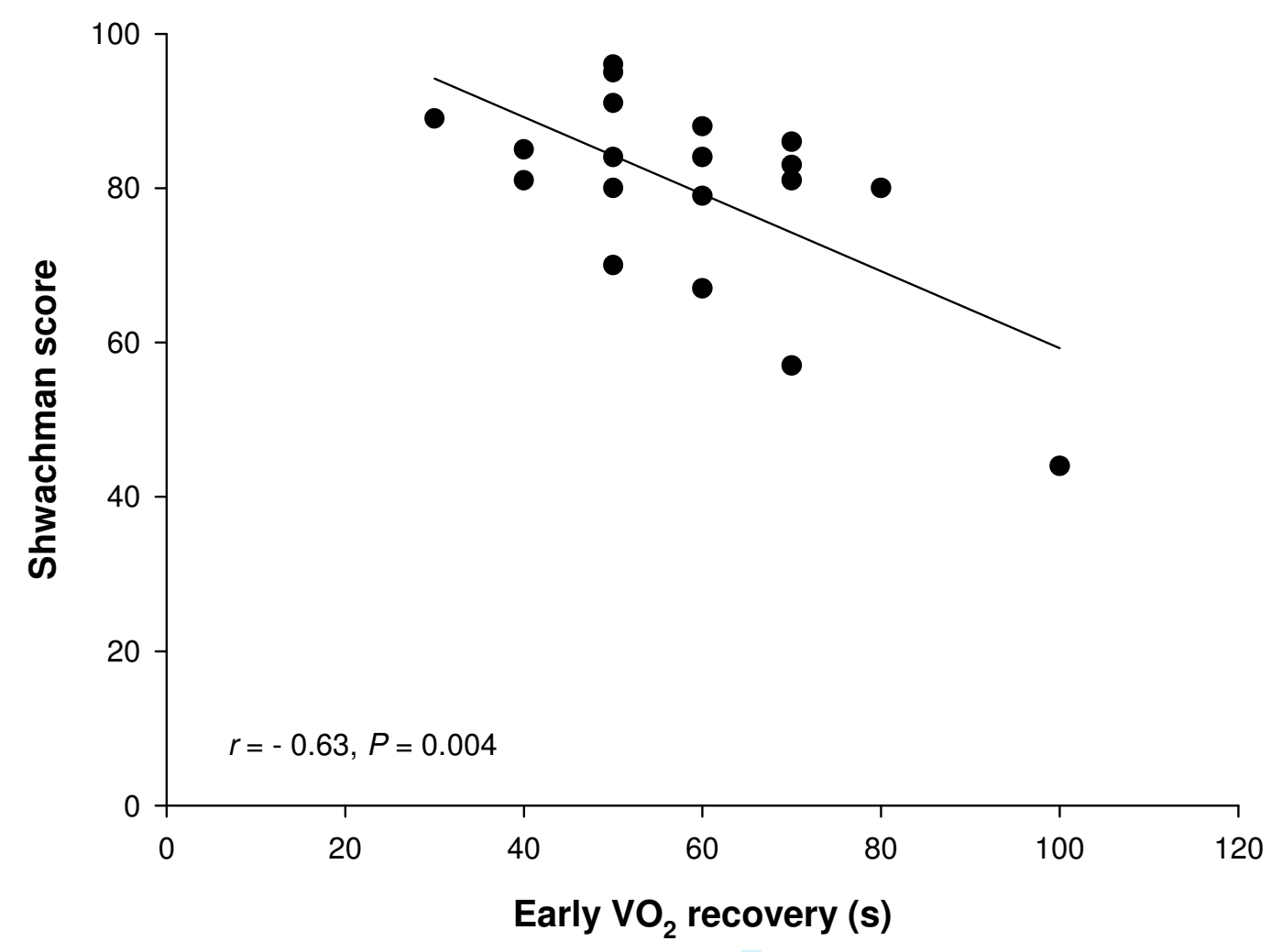




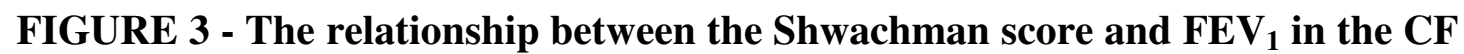
patients $(\mathbf{n}=19)$

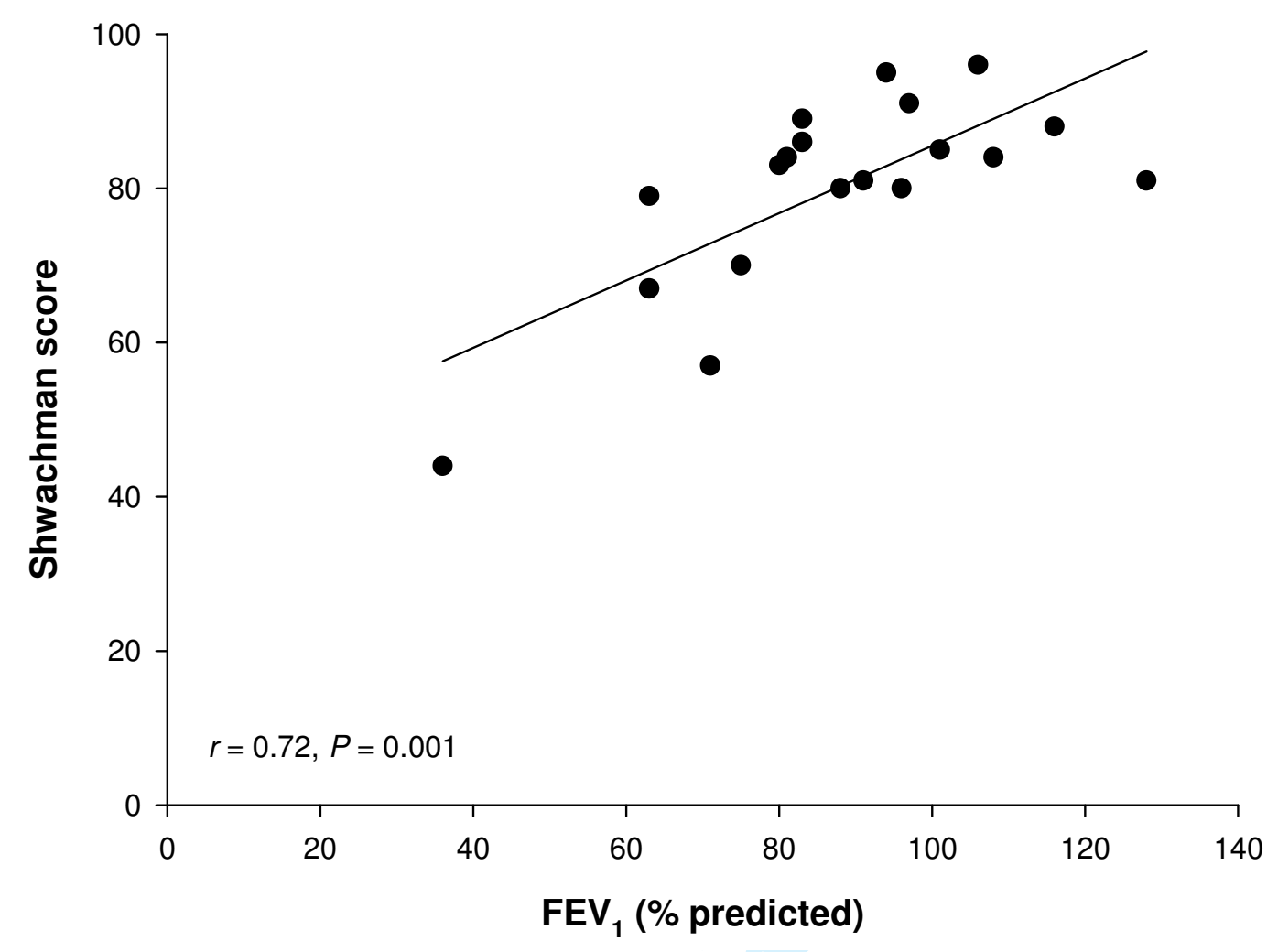


EARLY OXYGEN UPTAKE RECOVERY FOLLOWING EXERCISE TESTING IN CHILDREN WITH CHRONIC CHEST DISEASES

D. Stevens MSc, ${ }^{1}$ P.J. Oades FRCPCH, ${ }^{2}$ N. Armstrong D.Sc, ${ }^{1}$ and C.A. Williams Ph.D. ${ }^{1}$

${ }^{1}$ Children's Health and Exercise Research Centre, School of Sport and Health Sciences, University of Exeter, Exeter, Devon, UK. ${ }^{2}$ Royal Devon and Exeter NHS Foundation Trust Hospital, Exeter, Devon, UK.

The study was supported by the School of Sport and Health Sciences, University of Exeter, and the Royal Devon and Exeter NHS Foundation Trust Hospital.

Correspondence to: Craig A. Williams, Ph.D., Children's Health and Exercise, Research Centre, School of Sport and Health Sciences, University of Exeter, St. Luke's Campus, Heavitree Road, Exeter, UK. EX1 2LU

Tel: +44 (0) 1392 264890; Fax: +44 (0) 1392264726

Email: c.a.williams@exeter.ac.uk

Running head: RECOVERY FOLLOWING EXERCISE IN CHRONIC CHEST DISEASES 
Summary. The value of exercise testing as a prognostic measure of disease severity in patients with chronic chest diseases (CCD) is becoming increasingly recognised. The aim of this study was to investigate changes in oxygen uptake $\left(\dot{\mathrm{VO}}_{2}\right)$ during early recovery following maximal cardiopulmonary exercise testing (CPXT) in relation to functional capacity and markers of disease severity. Twenty-seven children with CCD (age $12.7 \pm 3.1 \mathrm{y} ; 17$ female) [Nineteen 19 children with Cystic fibrosis (CF) (age $13.4 \pm 3.1 \mathrm{y} ; 10$ female) and 8 with other stable non-CF chest diseases (NON-CF) with other stable CCD (age $11.1 \pm 2.2 \mathrm{y} ; 7$ female)] and 27 healthy controls (age $13.2 \pm 3.3$ y; 17 female) underwent CPXT on a cycle ergometer. On-line respiratory gas analysis measured $\dot{\mathrm{VO}}_{2}$ before and during CPXT to peak $\dot{\mathrm{VO}}_{2}$ ( $\dot{\mathrm{VO}}_{2}$ peak), and during the first $10 \mathrm{~min}$ of recovery. Early $\dot{\mathrm{VO}}_{2}$ recovery was quantified by the time (s) to reach $50 \%$ of the $\dot{\mathrm{VO}}_{2}$ peak value. Early $\dot{\mathrm{V}} \mathrm{O}_{2}$ recovery was correlated against lung function spirometry [forced expiratory volume in $1 \mathrm{~s}$ $\left(\mathrm{FEV}_{1}\right)$ and forced expiratory flow between 25 to $75 \%$ of the forced vital capacity $\left.\left(\mathrm{FEF}_{25-75}\right)\right]$ and aerobic fitness $\left(\dot{\mathrm{VO}}_{2}\right.$ peak $)$ as a measure of functional capacity. Disease severity was graded in the CF group patients by the Shwachman score (SS). Compared to controls, children with CCD demonstrated a significantly reduced $\dot{\mathrm{VO}}_{2 \text { peak }}(P=0.011), \mathrm{FEV}_{1}(P=0.000), \mathrm{FEF}_{25-75}(P=0.000)$, and a significantly prolonged early $\dot{\mathrm{VO}}_{2}$ recovery $(P=0.024)$. In the CF group patients the SS was significantly correlated with early $\dot{\mathrm{VO}}_{2}$ recovery $(r=-0.63, P=0.004), \mathrm{FEV}_{1}(r=$ $0.72, P=0.001)$ and $\mathrm{FEF}_{25-75}(r=0.57, P=0.011)$. The ratio- $\dot{\mathrm{v}} \mathrm{O}_{2 \text { peak }}\left(\mathrm{mL}^{\mathrm{i}} \mathrm{min}^{-1} \mathrm{~kg}^{-1}\right)$ Learly $\dot{\mathrm{V}} \mathrm{O}_{2}$ recovery $(\mathrm{s})(r-0.50, P-0.028)$ used in this study as a composite measure of exercise performance and recovery. In the children with $\mathrm{CCD}, \mathrm{FEV}_{1}$, $\mathrm{FEF}_{25-75}$ and $\mathrm{BMI}$ were not significantly correlated with $\dot{\mathrm{V}}{ }_{2}$ peak or early $\dot{\mathrm{VO}}_{2}$ 
recovery, indicating that lung function does not necessarily reflect aerobic fitness and the ability to recover from exercise in these patients. A significant relationship was found between $\dot{\mathrm{V}} \mathrm{O}_{2 \text { peak }}$ and early $\dot{\mathrm{V}} \mathrm{O}_{2}$ recovery $(r=-0.39, P=0.044)$ in the children with $\mathrm{CCD}$, showing that a greater aerobic fitness corresponded with a faster recovery. In the $\mathrm{CCD}$ group $\mathrm{FEV}_{1}$ was significantly lower compared to the $\mathrm{CF}$ group $(68 \pm 21$ vs $87 \pm 21 \%$ predicted, respectively; $P-0.044)$, however, no-significant differences were found between the groups for $\dot{\mathrm{v}} \mathrm{O}_{2}-(35.9 \pm 8.4 \mathrm{vs} 34.7 \pm 8.0$

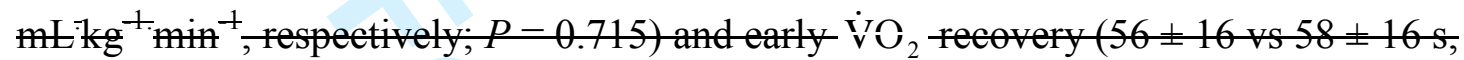
respectively; $P=0.755$ ). In children with $\mathrm{CF}$, early $\dot{\mathrm{v}} \mathrm{O}_{2}$ recovery following $\mathrm{CPXT}$ and $\mathrm{FEV}_{1}$ are significantly related to disease-severity. In children with CF and other $\mathrm{CCD}$, however, $\mathrm{FEV}_{1}$-does not fully reflect the ability to exercise and recover. Key words: chronic chest diseases, children, exercise testing, recovery, clinical measure 


\section{INTRODUCTION}

Exercise testing is a valuable tool for monitoring the physiological impact of chronic chest diseases (CCD). ${ }^{1}$ Exercise testing is incorporated in some paediatric respiratory centres as part of an annual assessment of children with Cystic fibrosis (CF), ${ }^{2}$ based on evidence demonstrating that aerobic and anaerobic exercise are limited, ${ }^{3}$ and that this limitation is related to survival. ${ }^{4}$ Peak oxygen uptake $\left(\mathrm{V}_{2}\right.$ peak $)$ during maximal cardiopulmonary exercise testing (CPXT) is considered the 'gold standard' measure for assessing aerobic fitness, ${ }^{1}$ and is an important measure for well-being and prognosis in CF. ${ }^{4,5}$ Lung function measured by spirometry, ${ }^{6}$ and $\dot{\mathrm{VO}}_{2}$ peak measured during $\mathrm{CPXT}^{7}$ are commonly measured to assess functional capacity and disease severity in patients with CF. Limited data exists, however, regarding recovery parameters following exercise testing in children with CCD.

During early recovery from exercise, phosphocreatine $(\mathrm{PCr})$ levels are inversely proportional to the rate of oxygen uptake $\left(\dot{\mathrm{VO}}_{2}\right)$, and dependent on the transport to and utilisation of oxygen $\left(\mathrm{O}_{2}\right)$ within contracting muscle. ${ }^{8,9}$ The importance of $\mathrm{O}_{2}$ in the resynthesis of PCr has been previously reported. ${ }^{10-13}$ Anaerobic glycolysis ceases at the termination of peak exercise, and oxidative phosphorylation provides the ATP required for $\mathrm{PCr}$ recovery. ${ }^{14}$ In cardiac diseases where the transportation and utilisation of $\mathrm{O}_{2}$ in the contracting muscle is adversely affected, $\mathrm{PCr}$ recovery time has been reported to be prolonged following exercise, ${ }^{15-18}$ whereas, a faster $\mathrm{PCr}$ recovery time has been demonstrated in healthy trained individuals. ${ }^{19}$ The rate of $\mathrm{PCr}$ resynthesis during recovery from exercise is, therefore, a reflection of oxidative capacity, and can be inferred from $\dot{\mathrm{VO}}_{2}$ measurements in children. ${ }^{20}$ 
We hypothesised that $\mathrm{PCr}$ resynthesis, as reflected by the $\dot{\mathrm{VO}}_{2}$ during early recovery from CPXT, is an index of the efficiency of maximal oxidative rate, and 1) will be prolonged in children with CCD compared to healthy controls, and 2) serve as an index of disease severity. Therefore, the aims of the study are to assess the $\mathrm{V}_{2}$ responses during early recovery from CPXT in children with $\mathrm{CCD}$ and healthy controls, and explore the relationships with markers of functional capacity and disease severity in children with CCD.

Assessing exercise performance is a valuable tool in monitoring health-status in eardiopulmonary disease ${ }^{+}$In chronic chest diseases (CCD), especially Cystic fibrosis (CF), exereise limitation is a mark of disease progression. ${ }^{21}$ The measurement of peak oxygen uptake ( $\dot{\mathrm{v}}_{2}$ ) during exercise testing is a measure of aerobic functional capacity and may predict prognosis in patients with $\mathrm{CF}^{4,22-24}$ Various exercise tests are incorporated into routine assessments of patients in CF centres. ${ }^{25}$ Information regarding exereise performance in young patients with other $\mathrm{CCD}$, however, is limited.

Many studies in CF to date have concentrated on the measurement of $\dot{\mathrm{v}}_{2}$ peak without considering measures of recovery. In adults, however, with heart disease ${ }^{26-30}$ and chronic obstructive pulmonary disease (COPD), ${ }^{31}$ the prognostic value of recovery measures following exercise testing have been investigated. Oxygen uptake $\left(\dot{\mathrm{VO}}_{2}\right)$ recovery time increases as ischaemic heart disease progresses ${ }^{28}$ and is prolonged in adults with heart failure ${ }^{29}$ when compared to controls ${ }^{27}$ and COPD. ${ }^{31}$ The metabolic cost of exercise results from both the performance of external work, and the demands of the oxygen transport system itself, including the work performed by the muscles for respiration and persistent hypermetabolism recognised during 
recovery. ${ }^{32}$ During early recovery, oxygen is primarily required for the rephosphorylation of creatine in skeletal muscles. The early rapid decline in - $\dot{\mathrm{v}}_{2}$ marks replenishment of muscle energy stores and the rate is an index of the efficiency of oxidative ATP resynthesis and this efficiency is reflected in an individual's functional capacity or ability to sustain repeated bouts of physical activity. Children with CF have less efficient oxidative ATP synthesis ${ }^{33}$ which could prolong the early $\dot{\mathrm{v}} \mathrm{O}_{2}$ recovery period after exercise.

\begin{abstract}
Assessing the rate at which the patient recovers from exereise may provide additionat information on current health-status. Following exercise the rate of recovery from the increased oxygen requirements in children with lung disease will be influenced by many disease factors including the presence of chronic infection and numerous physiological abnormalities which impair gas exchange and increase the work of breathing. An increase in dead space as the disease progresses, ${ }^{34}$-necessitates an increase in total ventilation in order to keep alveolar ventilation constant. ${ }^{35,36}$ Airway obstruction and air trapping reduces the rate of elimination of excess carbon dioxide formed during exercise, prolonging tachypnoea, which itself increases the metabolic demand for a given task and which contributes to fatigue. ${ }^{37}$ Delayed elimination of earbon dioxide also impairs the ability to compensate for alterations in acid based status. $^{38}$
\end{abstract}

The aim of this study, therefore, was to explore the relationship of markers of functional capacity and disease severity with early $\dot{\mathrm{v}} \mathrm{O}_{2}$ recovery in children with CF and other CCD. We hypothesised that early $\dot{\mathrm{v}} \mathrm{O}_{2}$ - recovery following maximat 
eardiopulmonary exercise testing (CPXT) is significantly related to other measures of disease severity and functional capacity in children with CF and other CCP.

\section{MATERIALS AND METHODS}

\section{Participants}

Twenty-seven children with CCD participated in the study (age $12.7 \pm 3.1 \mathrm{y} ; 17$ female). For further analysis the children with CCD were divided into two diagnostic groups. One group consisted of 19 children with CF (age $13.4 \pm 3.1 \mathrm{y} ; 10$ female), and the other group consisted of 8 children with other stable non-CF chest diseases (NONCF) (age $11.1 \pm 2.2 \mathrm{y} ; 7$ female) CCD diagnostic groups. The CF group consisted of 19 children (age $13.4 \pm 3.1 \mathrm{y} ; 10$ female), and the CCD group consisted of eight ehildren (age $11.1 \pm 2.2$ y; 7 female) [5 Non-CF bronchiectasis; 2 Primary ciliary dyskinesia; 1 Post-adenoviral obliterative bronchiolitis]. Twenty-seven healthy controls (age $13.2 \pm 3.3 \mathrm{y} ; 17$ female) free from any musculoskeletal, cardiovascular and pulmonary diseases that would compromise exercise performance were recruited from local schools and colleges in Devon, U.K. The controls were individually pair matched to the children with CCD for stature, body mass and pubertal maturity.

All participants volunteered for the study and written informed consent and assent was obtained from parents and participants, respectively. All children with CCD volunteered for the study and attended the outpatient clinic of the Royal Devon and Exeter NHS Foundation Trust Hospital. Written informed consent and assent was obtained from parents and children, respectively. All children with CCD were clinically stable at the time of CPXT, with no symptomatic deterioration over the preceding month. None had musculoskeletal conditions that would compromise 
exercise performance. Diagnosis of CF was based on clinical features supported by an abnormal sweat test (sweat chloride $>60 \mathrm{mmol} \mathrm{L}$ ) and in 17/19 diagnostic genotyping. Pubertal staging was assessed during routine outpatient clinic assessment by a trained nurse and classified as pre-, peri- and post- pubertal. ${ }^{39}$ The study was approved by the NHS Local Research Ethics Committee. Table 1 shows the anthropometric and physiological data of the CF and CCD.

\section{Maximal Cardiopulmonary Exercise Testing (CPXT)}

Infection control measures to prevent cross-infection were followed. Children with CCD were segregated in both waiting areas and testing places. Both equipment and the testing environment were cleaned using appropriate bacteriocidal wipes and solutions after each use.

Before CPXT all participants were instructed not to consume food or caffeine $2 \mathrm{hrs}$ before and wear light comfortable clothes suitable for exercising on a cycle. All The participants were also asked not to perform any strenuous exercise during $48 \mathrm{hrs}$ prior to the test time. Maximal cardiopulmonary exercise testing was performed on a cycle ergometer (Excaliber Sport; Lode, Groningen, The Netherlands) using a ramp protocol, commencing with unloaded pedalling for $2 \mathrm{~min}$ and then $10 \mathrm{~W}$ increases were made incrementally every min. All participants pedalled at a cadence of $70 \pm 5$ rpm and encouraged to continue until voluntary exhaustion. Peak oxygen uptake was determined by satisfying the following criteria; a respiratory exchange ratio $>1.06$; heart rate $>95 \%$ age related predicted maximum; scores of $8-10$ after exercise on a children's effort rating table (CERT); and clinically observed signs of facial flushing, 


\section{Assessment of Functional Capacity}

Peak oxygen uptake and lung function were used as markers of functional capacity. Peak oxygen uptake was used as a measure of aerobic fitness and expressed relative to body mass $\left(\mathrm{mL} \mathrm{kg}^{-1} \mathrm{~min}^{-1}\right)$. Lung function was assessed by forced expiratory volume in $1 \mathrm{~s}\left(\mathrm{FEV}_{1}\right)$, and forced expiratory flow between 25 to $75 \%$ of the forced vital capacity $\left(\mathrm{FEF}_{25-75}\right)$. All lung function measurements were and expressed as \% predicted, using appropriate reference data. ${ }^{40}$ Each participant's lung function was measured before the start of the CPXT. The forced expiratory manoeuvre was performed as recommended by the British Thoracic Society (1994) guidelines for the measurement of respiratory function, ${ }^{41}$ recording the best of three consistent exhalations, using an electronic spirometer (Microloop ML3535; Numed, Sheffield, UK).

\section{Assessment of Early $\dot{\mathrm{VO}}_{2}$ Recovery}


Early $\dot{\mathrm{VO}}_{2}$ recovery time was quantified by the time in seconds s from the cessation of exercise to reach $50 \%$ of the $\dot{\mathrm{V}}{ }_{2}$ peak value. This method has been described in previous studies to assess early $\dot{\mathrm{VO}}_{2}$ recovery in patients with cardiac diseases ehronic heart failure. ${ }^{26,27,42}$

\section{Assessment of Disease Severity for the Cystic Fibrosis Patients}

The Shwachman score (SS) was used to grade disease severity in the CF patients group, and was recorded prior to CPXT by the patient's clinician. The SS scores four separate aspects of the disease profile, general activity, physical examination, nutritional status and chest radiographic findings, using the most recent routine annual review chest $\mathrm{x}$-ray. Each disease profile is given an equal weighting of 25 points. A total of 100 points represents a perfect score of health. ${ }^{43}$

\section{Assessment of Composite Measure of Exercise Performance for the Cystic Fibrosis-Group \\ In this study a ratio of $\dot{\mathrm{v}} \mathrm{O}_{2}$ peak $\left(\mathrm{mL}^{-} \mathrm{min}^{-1} \mathrm{~kg}^{-1}\right) /$ early $\dot{\mathrm{v}} \mathrm{O}_{2}$-recovery (s) was alse used as a composite measure of exercise performance and recovery in the CF group.}

\section{Data Analysis}

Data were analysed using the Statistical Package for the Social Sciences (SPSS; version 11.0, Chicago, IL). The independent $t$-test was used for the comparison of the anthropometric and physiological data between children with CCD and controls the CF and groups. The Pearson product moment correlation was used to assess the association between $\dot{\mathrm{VO}}_{2}$ indexes and parameters of functional capacity and disease severity. Statistical significance was set a priori at $P<0.05$. 


\section{RESULTS}

The anthropometric data in Table 1 shows no significant differences in stature, body mass, BMI and pubertal maturity between the children with CCD and controls. The lung function data (Table 1) showed when compared to controls, children with CCD demonstrated significantly reduced $\mathrm{FEV}_{1}(P=0.000)$, FVC $(P=0.004)$, PEF $(P=$ 0.003), and $\mathrm{FEF}_{25-75}(P=0.000)$. Data from the CPXT (Table 2) showed that compared to controls the children with $\mathrm{CCD}$ had a significantly lower $\dot{\mathrm{V}}_{2}$ peak $(P=$ $0.011)$ and a significantly prolonged early $\dot{\mathrm{VO}}_{2}$ recovery $(P=0.024)$. Other CPXT data such as maximum workload $\left(\mathrm{W}_{\max }\right)$ was significantly lower $(P=0.009)$ in children with CCD compared to controls. Maximum heart rate $\left(\mathrm{HR}_{\max }\right)$ did not differ significantly between children with CCD and controls during CPXT (Table 2).

The correlation data (Table 3a) showed in the children with $\mathrm{CCD}, \mathrm{FEV}_{1}, \mathrm{FEF}_{25-75}$ and BMI were not significantly correlated with $\dot{\mathrm{VO}}_{2}$ peak or early $\dot{\mathrm{VO}}_{2}$ recovery. A significant negative relationship between $\dot{\mathrm{VO}}_{2}$ peak and early $\dot{\mathrm{VO}}_{2}$ recovery $(r=-$ $0.39, P=0.044$ ), however, was found in the children with CCD (Table 3a and Figure 1). Sub-group analysis within the children with $\mathrm{CCD}$ revealed, in the $\mathrm{CF}$ patients a significant negative correlation between the SS and early $\dot{\mathrm{V}} \mathrm{O}_{2}$ recovery $(r=-0.63, P$ $=0.004)$ (Table 3a and Figure 2), and significant correlations were also shown was also present between the SS and $\mathrm{FEV}_{1}(r=0.72, P=0.001)$ (Table $3 \mathrm{a}$ and Figure 3$)$, and $\mathrm{FEF}_{25-75}(r=0.57, P=0.011)$ (Table 3). No significant correlation, however, was found between the SS and $\mathrm{VO}_{2}$ peak $($ Table 2) in the CF patients (Table 3a). Between the $\mathrm{CF}$ and NON-CF patients no significant differences in $\dot{\mathrm{VO}}_{2}$ peak $(P=0.715)$ and early $\dot{\mathrm{VO}}_{2}$ recovery $(P=0.755)$ were shown, despite the NON-CF patients 
demonstrating a significantly reduced $\mathrm{FEV}_{1}(P=0.044)$ compared to the $\mathrm{CF}$ patients. Table $3 \mathrm{~b}$ shows the correlational relationships for the healthy control group, only BMI was found to be significantly correlated to recovery $(r=0.48, P=0.011)$.

There were no significant differences between the $C F$ and $C C D$ groups in age, stature and pubertal maturity (Table 1). Body mass, body mass index and $\mathrm{FEV}_{1}$ were significantly greater in the CF group than in the CCD group (Table 1). No significant differences were found between the CF group and CCD group in $\dot{\mathrm{V}} \mathrm{O}_{2}$ peak and early $\dot{\mathrm{v}} \mathrm{O}_{2}$-recovery (Table 1). No significant differences in the pulse oximetry data between the $\mathrm{CF}$ and $\mathrm{CCD}$ groups were found before or at the termination of $\mathrm{CPXT}$ (Table 1), but a significant fall in oxygen saturation before to the termination of CPXT was found in the CF group ( $97 \pm 1$ vs $94 \pm 2 \%$, respectively; $P=0.001$ ) and CCD group $(97 \pm 0.5 \%$ vs $96 \pm 1 \%$, respectively; $P=0.015)$.

In the CF group a significant negative correlation was found between the SS and early $\dot{\mathrm{v}}_{2}$ recovery (Table 2 and Figure 1), and a significant correlation was also present between the SS and $\mathrm{FEV}_{1}$ (Table 2 and Figure 2). No significant correlation was found between the SS and $\dot{\mathrm{v}} \mathrm{O}_{2 \text { peak }}$ (Table 2). Furthermore, amongst the children with CF, the ratio of $\dot{\mathrm{v}} \mathrm{O}_{2}$ peak $/$ early $\dot{\mathrm{v}}_{2}$-recovery was significantly correlated with the SS (Table 2 and Figure 3), but not with FEV F $_{4}$ Table 2).

In the CCD group early $\dot{\mathrm{v}} \mathrm{O}_{2}$-recovery had a significant negative relationship with $\dot{\mathrm{v}} \mathrm{O}_{2}$ peak (Table 3 and Figure 4), but not in the CF group (Table 2). No-signification correlations were found between early $\dot{\mathrm{V}}_{2}$ - recovery and $\mathrm{FEV}_{4}$-in either the $\mathrm{CF}$ 
group (Table 2) or the CCD group (Table 3). Similarly, FEV 1 -and $\dot{v}_{2}$ peak-were not found to be significantly related in either the CF group (Table 2) or CCD group (Table 3).

\section{DISCUSSION}

The present study found that compared to controls, children with CCD demonstrated a significantly reduced $\dot{\mathrm{V}}{ }_{2}$ peak and prolonged early $\dot{\mathrm{V}} \mathrm{O}_{2}$ recovery following CPXT. The metabolic cost of exercise results from both the performance of external work, and the demands of the $\mathrm{O}_{2}$ transportation system itself. This includes the work performed by the muscles of respiration and the enduring metabolic demand to restore homeostasis during recovery. ${ }^{32}$ The rate of $\dot{\mathrm{VO}}_{2}$ during early recovery from exercise in children with CCD will be influenced by many disease factors. For example, as disease progresses there is an increase in dead space, ${ }^{34}$ that necessitates an increase in total ventilation in order to keep alveolar ventilation constant. ${ }^{35,36}$ Airway obstruction and air trapping would also reduce the rate of elimination of excess carbon dioxide formed during exercise, prolonging tachypnoea, which itself would increase the metabolic demand and which contributes to fatigue. ${ }^{37}$ Delayed elimination of carbon dioxide would also impair the ability to compensate for alterations in acid-based status. ${ }^{38}$ Furthermore, in patients with $\mathrm{CF}$ the correlation between thin section computed tomographic (CT) findings of lung parenchymal damage and exercise limitation is stronger than that between spirometry results, or BMI and exercise limitation. ${ }^{44}$ The CF genotype has also been reported to be related to exercise tolerance. ${ }^{45}$ The aim of this study was to investigate if early $\dot{\mathrm{v}} \mathrm{O}_{2}$ recovery following CPXT was associated with disease severity and functional capacity in children with CF, and functional capacity in those with other CCD. 
The lung function data from the present study showed that $\mathrm{FEV}_{1}, \mathrm{FVC}, \mathrm{PEF}$ and $\mathrm{FEF}_{25-75}$ were all significantly reduced in children with $\mathrm{CCD}$ compared to controls. Forced expiratory volume in $1 \mathrm{~s}, \mathrm{FEF}_{25-75}$ and $\mathrm{BMI}$ in the children with $\mathrm{CCD}$, however, were not significantly correlated with $\dot{\mathrm{V}} \mathrm{O}_{2}$ peak or early $\dot{\mathrm{VO}}_{2}$ recovery. Furthermore, the study showed that despite a significantly reduced $\mathrm{FEV}_{1}$ in the NONCF patients compared to the $\mathrm{CF}$ patients, $\dot{\mathrm{VO}}_{2}$ peak and early $\dot{\mathrm{V}} \mathrm{O}_{2}$ recovery were not significantly different between the two patient groups. These findings demonstrate, therefore, that exercise performance was similar between the NON-CF and $\mathrm{CF}$ patients, despite poorer lung function in the NON-CF patients. These finding may emphasise the physiological differences between the static nature of lung function testing and the dynamic nature of the cardiopulmonary system when exercising. It may also infer, however, the physiological differences between children with CF and other $\mathrm{CCD}$, especially in regard to recent work which found that $\mathrm{CF}$ patients demonstrated reduced oxidative work efficiency in the skeletal muscle. ${ }^{33}$

Contrary to previous studies which have reported that reduced $\mathrm{FEV}_{1}$ is associated with lower $\dot{\mathrm{VO}}_{2}$ peak, ${ }^{21,34,46-49}$ a non-significant relationship between lung function and $\dot{\mathrm{V}}{ }_{2}$ peak in the children with CCD in the present study may provide further support to work which has reported that reduced aerobic performance is related to intrinsic abnormalities of skeletal muscle function. ${ }^{33,50-52}$ Furthermore, a recent study reported that $\dot{\mathrm{V}} \mathrm{O}_{2}$ peak and exercise duration during CPXT was not affected in patients with mild CF using added dead space, suggesting the CPXT is not limited by respiratory factors. ${ }^{53}$ Moser et al. (2000) also found no significant correlations between variables 
In children with CF a significant relationship between early $\dot{\mathrm{VO}}_{2}$ recovery and the SS was found. Correlations between structural abnormalities of the lung scored on thin section CT images and exercise performance have been reported in patients with $\mathrm{CF}$, and these relationships are stronger than that between spirometry results, or BMI and exercise limitation, ${ }^{44}$ and may explain the relationship found in the present study. Based on the results of this study early $\dot{\mathrm{v}}_{2}$-recovery has value as an objective measure of disease severity in children with CF. Forced expiratory volume in $1 \mathrm{~s}$ and $\mathrm{FEF}_{25-75}$ in the children with $\mathrm{CF}$ were also significantly related to the SS A significant relationship was also found in the CF group between $\mathrm{FEV}_{1}$ and the SS, confirming previous reports that lung function is correlated with disease severity and survival in

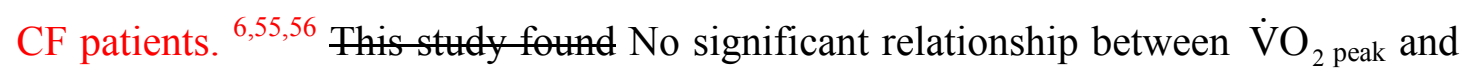
the SS in the CF patients group was found in the present study. The $\dot{\mathrm{VO}}_{2}$ peak values 
for children with CF in this study are similar to published values of aerobic fitness for young CF patients of a similar age range. ${ }^{23,24,51}$ A significant correlation between $\dot{\mathrm{V}} \mathrm{O}_{2}$ peak and SS has been previously reported in adults with $\mathrm{CF},{ }^{57}$ but not in children. The disease severity of the adult CF patients was greater than in the present study (71 \pm 14 versus $80 \pm 12$, respectively) and $\dot{\mathrm{V}}{ }_{2}$ peak was lower $(25 \pm 7$ versus $35 \pm 8$ $\mathrm{mL} \mathrm{kg}^{-1} \mathrm{~min}^{-1}$, respectively), which may have increased the likelihood of finding a significant relationship due to a greater heterogeneity of the correlated variables.

No-significant differences in $\dot{\mathrm{v}} \mathrm{O}_{2}$ peak $-\mathrm{or}$ early $\dot{\mathrm{v}}_{2}$ recovery between the $\mathrm{CF}$ and CCD groups were found despite the children in the CCD group having a significantly reduced $\mathrm{FEV}_{1}$. This finding signifies that static airway obstruction as measured by $\mathrm{FEV}_{1}$ for the range of values in this stuly did not affect either group's ability to utilise exygen either during or immediately following CPXT. Furthermore, it emphasises the physiological differences between the static nature of pulmonary function testing and the dynamic nature of the pulmonary/respiratory system when exercising. This may explain why $\mathrm{FEV} \mathrm{V}_{1}$-was not significantly related to $\dot{\mathrm{v}}_{2}$ peak and early $\dot{\mathrm{v}}_{2}$ recovery in either groups. Therefore, this study found that in children with CF and other CCD, $\mathrm{FEV}_{4}$ is a poor predictor of exercise performance and recovery.

A significant relationship was found between early $\dot{\mathrm{v}}_{2}$ recovery and $\dot{\mathrm{v}}_{2}$ peak in the CCD group but not the CF group. Therefore, $\dot{\mathrm{v}}_{2}$ is a $\mathrm{i}_{\mathrm{k}}$ a good predictor of early $\dot{\mathrm{v}}_{2}$ recovery in children with CCD but not in children with CF. This finding may reflect more disease variables and physiological differences between the $C F$ and $C C D$ groups. Published work has reported that impaired exercise performance in young CF 
Using the ratio of $\dot{\mathrm{v}} \mathrm{O}_{2}$ peak $/$ early $\dot{\mathrm{v}} \mathrm{O}_{2}$ recovery as a composite measure of exercise performance, a significant correlation was found with the SS in the CF group and, therefore, may be an objective measure of disease severity. Recovery time may refine the $\dot{\mathrm{v}}_{2}$ peak measure, and the ratio of the two measures may provide a comprehensive exercise performance score. For example, where patients with higher aerobic capacity and who recover more quickly have greater physical ability than those with high aerobic capacity but slower recovery, or those with low aerobic capacity and slow recovery. More research, however, is needed to verify this measure and the data in this study is preliminary.

Many studies of therapeutic interventions use lung function variables as the primary outcome. ${ }^{59-63}$ Disease in CF can progress as shown on thoracic High Resolution Computerised Tomography Scanning despite lung function stability. ${ }^{64}$ Exercise parameters may provide a more integrated outcome measure. Exercise involves the amalgamation of respiratory, cardiovaseular, metabolic, nutritional and psychologicat systems and therefore measures of performance are more likely to reflect health-status than a single static test such as spirometric lung function. Exercise performance as measured by $\dot{\mathrm{v}} \mathrm{O}_{2}$ peak has been shown to have a closer correlation with prospective mortality than resting lung function in CF. ${ }^{4}$ Exercise testing can provide useful 
additional information about functional limitations and trends over time. ${ }^{65}$ The links between more detailed measures of exercise performance including recovery parameters, disease severity and quality of life deserve more attention. Objective measures may be more accurate in predicting prognosis and mapping progress and response to treatments than more subjective scoring systems of well being. Peak exygen uptake alone may have limitations and a more composite measure of exercise performance that includes the rate of recovery may be more meaningful.

In conclusion, children with CCD in the present study had mild to moderate disease as interpreted by their lung function, and showed a reduced $\dot{\mathrm{VO}}_{2}$ peak and prolonged early $\dot{\mathrm{VO}}_{2}$ recovery compared to a control group. The prolonged recovery may be an indication of reduced oxidative capacity for $\mathrm{PCr}$ resynthesis, attributed to impaired $\mathrm{O}_{2}$ transportation and utilisation in the contracting muscle. Indeed, the present study showed that early $\dot{\mathrm{VO}}_{2}$ recovery was significantly related to the SS in children with $\mathrm{CF}$, indicating that early $\dot{\mathrm{VO}}_{2}$ recovery is prolonged with increased disease severity. Lung function was not significantly related to $\dot{\mathrm{V}} \mathrm{O}_{2}$ peak and early $\dot{\mathrm{V}} \mathrm{O}_{2}$ recovery, and therefore may not accurately reflect the patient's ability to exercise and recover. Indeed, disease in CF can progress significantly, as shown on thoracic high resolution CT scanning, despite lung function stability. ${ }^{64}$ Exercise testing can help to provide useful additional information about functional limitations and trends over time. ${ }^{65} \mathrm{~A}$ recent study reported that higher aerobic fitness despite poor lung function is associated with a better prognosis. ${ }^{23}$ The links between more detailed measures of exercise performance including recovery parameters, disease severity and quality of life deserve more attention and warrant further investigation. Furthermore, the present 


\section{ACKNOWLEDGMENTS}

The authors would like to thank the staff at the Paediatric Unit (Bramble Ward), Royal Devon and Exeter NHS Foundation Trust Hospital, for their help and assistance, and to the technical staff at the School of Sport and Health Sciences, University of Exeter, for their support. Finally, the authors would like to express their appreciation to the children who participated in this study. The study was supported by funds from the School of Sport and Health Sciences, University of Exeter, and the Research and Development department, Royal Devon and Exeter NHS Foundation Trust Hospital. The authors declare that there are no conflicts of interest in this study. 


\section{REFERENCES}

1. Palange P, Ward SA, Carlsen KH, Casaburi R, Gallagher CG, Gosselink R, O'Donnell DE, Puente-Maestu L, Schols AM, Singh S, Whipp BJ. Recommendations on the use of exercise testing in clinical practice. Eur Respir J 2007;29(1):185-209.

2. Orenstein DM. Exercise testing in cystic fibrosis. Pediatr Pulmonol 1998;25(4):223-225.

3. Shah AR, Gozal D, Keens TG. Determinants of aerobic and anaerobic exercise performance in cystic fibrosis. Am J Respir Crit Care Med 1998;157(4 Pt 1):1145-1150.

4. Nixon PA, Orenstein DM, Kelsey SF, Doershuk CF. The prognostic value of exercise testing in patients with cystic fibrosis. New England Journal of Medicine 1992;327(25):1785-1788.

5. Orenstein DM, Nixon PA, Ross EA, Kaplan RM. The quality of well-being in cystic fibrosis. Chest 1989;95(2):344-347.

6. Kerem E, Reisman J, Corey M, Canny GJ, Levison H. Prediction of mortality in patients with cystic fibrosis. N Engl J Med 1992;326(18):1187-1191.

7. Webb AK, Dodd ME, Moorcroft J. Exercise and cystic fibrosis. J R Soc Med 1995;88 Suppl 25:30-36.

8. Mahler M. First-order kinetics of muscle oxygen consumption, and an equivalent proportionality between QO2 and phosphorylcreatine level. Implications for the control of respiration. J Gen Physiol 1985;86(1):135-165.

9. Meyer RA. A linear model of muscle respiration explains monoexponential phosphocreatine changes. Am J Physiol 1988;254(4 Pt 1):C548-553.

10. Harris RC, Edwards RH, Hultman E, Nordesjo LO, Nylind B, Sahlin K. The time course of phosphorylcreatine resynthesis during recovery of the quadriceps muscle in man. Pflugers Arch 1976;367(2):137-142.

11. Sahlin K, Harris RC, Hultman E. Resynthesis of creatine phosphate in human muscle after exercise in relation to intramuscular $\mathrm{pH}$ and availability of oxygen. Scand J Clin Lab Invest 1979;39(6):551-558.

12. Taylor DJ, Bore PJ, Styles P, Gadian DG, Radda GK. Bioenergetics of intact human muscle. A 31P nuclear magnetic resonance study. Mol Biol Med 1983;1(1):77-94.

13. Quistorff B, Johansen L, Sahlin K. Absence of phosphocreatine resynthesis in human calf muscle during ischaemic recovery. Biochem J 1993;291 ( Pt 3):681-686. 
14. McMahon S, Jenkins D. Factors affecting the rate of phosphocreatine resynthesis following intense exercise. Sports Med 2002;32(12):761-784.

15. Massie BM, Conway M, Yonge R, Frostick S, Sleight P, Ledingham J, Radda G, Rajagopalan B. 31P nuclear magnetic resonance evidence of abnormal skeletal muscle metabolism in patients with congestive heart failure. Am J Cardiol 1987;60(4):309-315.

16. Mancini DM, Ferraro N, Tuchler M, Chance B, Wilson JR. Detection of abnormal calf muscle metabolism in patients with heart failure using phosphorus-31 nuclear magnetic resonance. Am J Cardiol 1988;62(17):12341240 .

17. Chati Z, Zannad F, Robin-Lherbier B, Escanye JM, Jeandel C, Robert J, Aliot E. Contribution of specific skeletal muscle metabolic abnormalities to limitation of exercise capacity in patients with chronic heart failure: a phosphorus 31 nuclear magnetic resonance study. Am Heart J 1994;128(4):781-792.

18. Belardinelli R, Barstow TJ, Nguyen P, Wasserman K. Skeletal muscle oxygenation and oxygen uptake kinetics following constant work rate exercise in chronic congestive heart failure. Am J Cardiol 1997;80(10):1319-1324.

19. McCully KK, Vandenborne K, DeMeirleir K, Posner JD, Leigh JS, Jr. Muscle metabolism in track athletes, using 31P magnetic resonance spectroscopy. Can J Physiol Pharmacol 1992;70(10):1353-1359.

20. Barker AR, Welsman JR, Fulford J, Welford D, Williams CA, Armstrong N. Muscle phosphocreatine and pulmonary oxygen uptake kinetics in children at the onset and offset of moderate intensity exercise. Eur J Appl Physiol 2008;102(6):727-738.

21. Cropp GJ, Pullano TP, Cerny FJ, Nathanson IT. Exercise tolerance and cardiorespiratory adjustments at peak work capacity in cystic fibrosis. Am Rev Respir Dis 1982;126(2):211-216.

22. Moorcroft AJ, Dodd ME, Webb AK. Exercise testing and prognosis in adult cystic fibrosis. Thorax 1997;52(3):291-293.

23. Pianosi P, Leblanc J, Almudevar A. Peak oxygen uptake and mortality in children with cystic fibrosis. Thorax 2005;60(1):50-54.

24. Javadpour SM, Selvadurai H, Wilkes DL, Schneiderman-Walker J, Coates AL. Does carbon dioxide retention during exercise predict a more rapid decline in FEV1 in cystic fibrosis? Archives of Disease in Childhood 2005;90(8):792-795.

25. Orenstein DM, Higgins LW. Update on the role of exercise in cystic fibrosis. Curr Opin Pulm Med 2005;11(6):519-523. 
26. Nanas S, Nanas J, Kassiotis C, Nikolaou C, Tsagalou E, Sakellariou D, Terovitis I, Papazachou O, Drakos S, Papamichalopoulos A, Roussos C. Early recovery of oxygen kinetics after submaximal exercise test predicts functional capacity in patients with chronic heart failure. Eur J Heart Fail 2001;3(6):685692.

27. Tanabe Y, Takahashi M, Hosaka Y, Ito M, Ito E, Suzuki K. Prolonged recovery of cardiac output after maximal exercise in patients with chronic heart failure. J Am Coll Cardiol 2000;35(5):1228-1236.

28. Pavia L, Myers J, Cesare R. Recovery kinetics of oxygen uptake and heart rate in patients with coronary artery disease and heart failure. Chest 1999;116(3):808-813.

29. Mitchell SH, Steele NP, Leclerc KM, Sullivan M, Levy WC. Oxygen cost of exercise is increased in heart failure after accounting for recovery costs. Chest 2003;124(2):572-579.

30. Myers J, Gianrossi R, Schwitter J, Wagner D, Dubach P. Effect of exercise training on postexercise oxygen uptake kinetics in patients with reduced ventricular function. Chest 2001;120(4):1206-1211.

31. Chick TW, Cagle TG, Vegas FA, Poliner JK, Murata GH. Recovery of gas exchange variables and heart rate after maximal exercise in COPD. Chest 1990;97(2):276-279.

32. Gaesser GA, Brooks GA. Metabolic bases of excess post-exercise oxygen consumption: a review. Med Sci Sports Exerc 1984;16(1):29-43.

33. de Meer K, Jeneson JA, Gulmans VA, van der Laag J, Berger R. Efficiency of oxidative work performance of skeletal muscle in patients with cystic fibrosis. Thorax 1995;50(9):980-983.

34. Godfrey S, Mearns M. Pulmonary function and response to exercise in cystic fibrosis. Archives of Disease in Childhood 1971;46(246):144-151.

35. Hirsch JA, Zhang SP, Rudnick MP, Cerny FJ, Cropp GJ. Resting oxygen consumption and ventilation in cystic fibrosis. Pediatr Pulmonol 1989;6(1):1926.

36. Coates AL, Canny G, Zinman R, Grisdale R, Desmond K, Roumeliotis D, Levison $\mathrm{H}$. The effects of chronic airflow limitation, increased dead space, and the pattern of ventilation on gas exchange during maximal exercise in advanced cystic fibrosis. Am Rev Respir Dis 1988;138(6):1524-1531.

37. Gallagher CG, Younes M. Breathing pattern during and after maximal exercise in patients with chronic obstructive lung disease, interstitial lung disease, and cardiac disease, and in normal subjects. Am Rev Respir Dis 1986;133(4):581-586. 
38. Chonan T, elHefnawy AM, Simonetti OP, Cherniack NS. Rate of elimination of excess CO2 in humans. Respir Physiol 1988;73(3):379-394.

39. Tanner JM. Growth at Adolescence, 2nd Edition. Oxford: Blackwell Scientific Publications; 1962.

40. Zapletal A, Samanek M, Paul T. Lung function in children and adolescents. Methods, reference values. In: Zapletal A, editor. Progress in Respiration Research. Volume 22; 1987. p 114-116.

41. Guidelines for the measurement of respiratory function. Recommendations of the British Thoracic Society and the Association of Respiratory Technicians and Physiologists. Respir Med 1994;88(3):165-194.

42. Cohen-Solal A, Laperche T, Morvan D, Geneves M, Caviezel B, Gourgon R. Prolonged kinetics of recovery of oxygen consumption after maximal graded exercise in patients with chronic heart failure. Analysis with gas exchange measurements and NMR spectroscopy. Circulation 1995;91(12):2924-2932.

43. Shwachman H, Kulczycki LL. Long-term study of one hundred five patients with cystic fibrosis; studies made over a five- to fourteen-year period. AMA J Dis Child 1958;96(1):6-15.

44. Dodd JD, Barry SC, Barry RB, Gallagher CG, Skehan SJ, Masterson JB. Thin-section CT in patients with cystic fibrosis: correlation with peak exercise capacity and body mass index. Radiology 2006;240(1):236-245.

45. Selvadurai HC, McKay KO, Blimkie CJ, Cooper PJ, Mellis CM, Van Asperen $\mathrm{PP}$. The relationship between genotype and exercise tolerance in children with cystic fibrosis. Am J Respir Crit Care Med 2002;165(6):762-765.

46. Cerny FJ, Pullano TP, Cropp GJ. Cardiorespiratory adaptations to exercise in cystic fibrosis. Am Rev Respir Dis 1982;126(2):217-220.

47. Marcotte JE, Canny GJ, Grisdale R, Desmond K, Corey M, Zinman R, Levison H, Coates AL. Effects of nutritional status on exercise performance in advanced cystic fibrosis. Chest 1986;90(3):375-379.

48. Marcotte JE, Grisdale RK, Levison H, Coates AL, Canny GJ. Multiple factors limit exercise capacity in cystic fibrosis. Pediatr Pulmonol 1986;2(5):274-281.

49. Lands LC, Heigenhauser GJ, Jones NL. Analysis of factors limiting maximal exercise performance in cystic fibrosis. Clin Sci (Lond) 1992;83(4):391-397.

50. Kusenbach G, Wieching R, Barker M, Hoffmann U, Essfeld D. Effects of hyperoxia on oxygen uptake kinetics in cystic fibrosis patients as determined by pseudo-random binary sequence exercise. Eur J Appl Physiol Occup Physiol 1999;79(2):192-196. 
51. Moser C, Tirakitsoontorn P, Nussbaum E, Newcomb R, Cooper DM. Muscle size and cardiorespiratory response to exercise in cystic fibrosis. American Journal of Respiratory and Critical Care Medicine 2000;162(5):1823-1827.

52. Selvadurai HC, Allen J, Sachinwalla T, Macauley J, Blimkie CJ, Van Asperen PP. Muscle function and resting energy expenditure in female athletes with cystic fibrosis. Am J Respir Crit Care Med 2003;168(12):1476-1480.

53. Dodd JD, Barry SC, Gallagher CG. Respiratory factors do not limit maximal symptom-limited exercise in patients with mild cystic fibrosis lung disease. Respir Physiol Neurobiol 2006;152(2):176-185.

54. Edwards EA, Narang I, Li A, Hansell DM, Rosenthal M, Bush A. HRCT lung abnormalities are not a surrogate for exercise limitation in bronchiectasis. Eur Respir J 2004;24(4):538-544.

55. Huang NN, Schidlow DV, Szatrowski TH, Palmer J, Laraya-Cuasay LR, Yeung W, Hardy K, Quitell L, Fiel S. Clinical features, survival rate, and prognostic factors in young adults with cystic fibrosis. Am $\mathrm{J}$ Med 1987;82(5):871-879.

56. Sharples L, Hathaway T, Dennis C, Caine N, Higenbottam T, Wallwork J. Prognosis of patients with cystic fibrosis awaiting heart and lung transplantation. J Heart Lung Transplant 1993;12(4):669-674.

57. Pouliou E, Nanas S, Papamichalopoulos A, Kyprianou T, Perpati G, Mavrou I, Roussos C. Prolonged oxygen kinetics during early recovery from maximal exercise in adult patients with cystic fibrosis. Chest 2001;119(4):1073-1078.

58. de Meer K, Gulmans VA, van Der Laag J. Peripheral muscle weakness and exercise capacity in children with cystic fibrosis. American Journal of Respiratory and Critical Care Medicine 1999;159(3):748-754.

59. Orenstein DM, Franklin BA, Doershuk CF, Hellerstein HK, Germann KJ, Horowitz JG, Stern RC. Exercise conditioning and cardiopulmonary fitness in cystic fibrosis. The effects of a three-month supervised running program. Chest 1981;80(4):392-398.

60. Zach M, Oberwaldner B, Hausler F. Cystic fibrosis: physical exercise versus chest physiotherapy. Arch Dis Child 1982;57(8):587-589.

61. Stanghelle JK, Hjeltnes N, Bangstad HJ, Michalsen H. Effect of daily short bouts of trampoline exercise during 8 weeks on the pulmonary function and the maximal oxygen uptake of children with cystic fibrosis. Int J Sports Med 1988;9 Suppl 1:32-36.

62. Cerny FJ. Relative effects of bronchial drainage and exercise for in-hospital care of patients with cystic fibrosis. Phys Ther 1989;69(8):633-639. 
63. Selvadurai HC, Blimkie CJ, Meyers N, Mellis CM, Cooper PJ, Van Asperen PP. Randomized controlled study of in-hospital exercise training programs in children with cystic fibrosis. Pediatric Pulmonology 2002;33(3):194-200.

64. de Jong PA, Nakano Y, Lequin MH, Mayo JR, Woods R, Pare PD, Tiddens HA. Progressive damage on high resolution computed tomography despite stable lung function in cystic fibrosis. Eur Respir J 2004;23(1):93-97.

65. Stevens D, Williams CA. Exercise testing and training with the young Cystic fibrosis patient. Journal of Sports Science and Medicine 2007;6:286-291. 